\title{
Sub-surface damage issues for effective fabrication of large optics
}

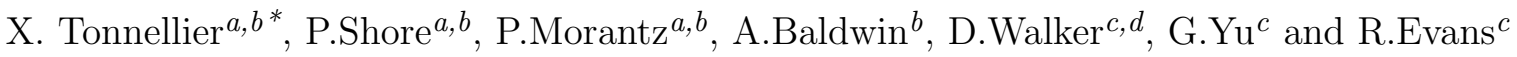 \\ ${ }^{a}$ Ultra Precision and Structured Surfaces Centre, Optic Technium, LL17 OJD, UK \\ ${ }^{b}$ Cranfield University Precision Engineering Centre, Cranfield University, MK43 0AL, UK \\ ${ }^{c}$ National Facility for Ultra Precision Surfaces, Optic Technium, LL17 OJD, UK \\ 'Zeeko Ltd, Coalville, Leicester, LE67 3FW, UK
}

\begin{abstract}
A new ultra precision large optics grinding machine, BoX ${ }^{\mathbb{B}}$, has been developed at Cranfield University. BoX ${ }^{\mathbb{B}}$ is located at the UK's Ultra Precision Surfaces laboratory at the OpTIC Technium. This machine offers a rapid and economic solution for grinding large off-axis aspherical and free-form optical components.

This paper presents an analysis of subsurface damage assessments of optical ground materials produced using diamond resin bonded grinding wheels. The specific materials used, Zerodur ${ }^{\mathbb{B}}$ and ULE ${ }^{\mathbb{B}}$ are currently under study for making extremely large telescope (ELT) segmented mirrors such as in the E-ELT project.

The grinding experiments have been conducted on the BoX ${ }^{\mathbb{B}}$ grinding machine using wheels with grits sizes of $76 \mu \mathrm{m}, 46 \mu \mathrm{m}$ and $25 \mu \mathrm{m}$. Grinding process data was collected using a Kistler dynamometer platform. The highest material removal rate $\left(187.5 \mathrm{~mm}^{3} / \mathrm{s}\right)$ used ensures that a 1 metre diameter optic can be ground in less than 10 hours. The surface roughness and surface profile were measured using a Form Talysurf. The subsurface damage was revealed using a sub aperture polishing process in combination with an etching technique.

These results are compared with the targeted form accuracy of $1 \mu \mathrm{m}$ p-v over a 1 metre part, surface roughness of 50-150 nm RMS and subsurface damage in the range of 2-5 $\mu \mathrm{m}$. This process stage was validated on a 400 $\mathrm{mm} \mathrm{ULE}^{(\mathbb{B})}$ blank and a 1 metre hexagonal Zerodur ${ }^{\mathbb{B}}$ part.
\end{abstract}

Keywords: Diamonds resin bond grinding wheel, Grinding, Subsurface damage, Zerodur, ULE, Machine dynamics

\section{INTRODUCTION}

\subsection{Technologies challenges}

A number of projects are studying the possibility of making a next generation of Extremely Large Telescopes (ELT).

At the end of 2006, two concepts, Euro50 and OWL, ${ }^{1}$ were merged by the European community into a new project, the European Extremely Large Telescope ${ }^{2}$ (E-ELT). This telescope will have a $42 \mathrm{~m}$ primary mirror made from 906 segments each of $1.45 \mathrm{~m}$ size with a hexagonal shape.

The potential materials for such segments are glass, glass ceramic or ceramic. ${ }^{3}$ Low thermal expansion glass and glass ceramics, such as $\mathrm{ULE}^{\mathbb{B}}$ and Zerodur ${ }^{\mathbb{B}}$ respectively, have been employed for many years in the manufacturing of large optics.

Sagem and Kodak have reported manufacturing process concepts for making $>1$ metre hexagonal mirrors. The blank is progressively ground to reach the desired shape. Then, the mirror is lapped and polished to get the correct form geometry and to remove any subsurface damage induced by previous machining process. ${ }^{4}$

A possible production improvement is to achieve a grinding process that is capable of producing better shaped surfaces having less subsurface damage and at higher material removal rates. To achieve this production capability, a new ultra precision large optics grinder ${ }^{5}-\mathrm{BoX}^{\mathbb{B}}$ - has been developed at Cranfield University.

During this machine development, grinding processes were tested on a 5-axis Holroyd Edgetek grinding machine. A dedicated fixture was used in order to simulate the BoX ${ }^{\circledR}$ grinding mode. ${ }^{6}$ The grinding forces and power, ${ }^{7}$

*x.p.tonnellier@cranfield.ac.uk, Telephone: +44 (0)1745 535 143, www.cranfield.ac.uk/sas

Advanced Optical and Mechanical Technologies in Telescopes and Instrumentation, edited by Eli Atad-Ettedgui, Dietrich Lemke, Proc. of SPIE Vol. 7018, 70180F, (2008) · 0277-786X/08/\$18 · doi: 10.1117/12.790639 
as well as the wheel wear ${ }^{8}$ induced by this particular grinding mode have previously been reported.

The Box ${ }^{\circledR}$ grinding machine is part of an Ultra Precision and Structured Surfaces (UPS ${ }^{2}$ ) facility, in Technium OpTIC, St Asaph, North Wales. ${ }^{9}$

\subsection{Ultra Precision and Structured Surfaces $\left(\right.$ UPS $\left.^{2}\right)$ facility ${ }^{9}$}

The $£ 15$ million Technium OpTIC, based in St Asaph, North Wales, is a significant initiative of the Welsh Optics Forum. This facility houses a temperature controlled Ultra Precision Surfaces (UPS) laboratory. ${ }^{9}$ Containing UK world's most effective ultra precision machining systems for large optics fabrication.

- BoX ${ }^{\circledR}$ ultra-precision large optics grinder (2 metres capacity) developed at Cranfield University

- Zeeko ultra-precision polishing machine, 1.2 metres capacity embodying classic, abrasive pad and fluid jet polishing technologies.

- Reactive Atom Plasma surface finishing facility developed by RAPT Industries in partnership with Cranfield University.

The laboratory also has a full suite of surface metrology equipment, including high measurement interferometers: stability for form measurement, miniature high accuracy interferometers, and white-light scanning interferometers. In addition, it houses a large optics swing arm profilometer developed by the UK's National Physical Laboratory.

\subsection{Results discussed}

The purpose of the work described in this paper has been to establish the level of subsurface damage (SSD) in $\mathrm{ULE}^{(\mathbb{B}}$ and Zerodur ${ }^{\mathbb{B}}$ using different material removal rates. A comparison of surface roughness and SSD qualities is provided in relation to grinding parameters. This work was carried out on the BoX ${ }^{\mathbb{B}}$ grinding machine on 100 mm square specimens.

This process was repeated on a $400 \mathrm{~mm}$ square $\mathrm{ULE}^{(\mathbb{B})}$ part and on a $1 \mathrm{~m}$ Zerodur ${ }^{\mathbb{B}}$ hexagonal part. A highest material removal rate $\left(187.5 \mathrm{~mm}^{3} / \mathrm{s}\right)$ was used to ensure that a 1 metre diameter optic can be ground in less than 10 hours. The results are compared with the targeted form accuracy of $1 \mu \mathrm{m} \mathrm{p}-\mathrm{v}$ over a 1 metre part, surface roughness of 50-150 nm RMS and subsurface damage in the range of 2-5 $\mu \mathrm{m}$.

\section{SUBSURFACE DAMAGE EVALUATION OF BRITTLE MATERIALS}

\subsection{Subsurface damage mechanisms}

Ductile or brittle fracture mode grinding ${ }^{10}$ can be used to machine brittle materials such as Zerodur ${ }^{\mathbb{B}}$ and $\mathrm{ULE}^{\mathbb{B}}$. Ductile mode grinding has been reported to give low subsurface damage ${ }^{11}$ (SSD). However, achievable material removal rate is low, as for example the critical depth of cut is $\sim 50 \mathrm{~nm}^{12}$ on Zerodur ${ }^{\circledR}$.

Higher manufacturing rates are supported using micro brittle fracture grinding. However, the brittle mode leaves surface and subsurface damage on ground surfaces. An efficient grinding process requires optimisation of the grinding parameters to reduce the level of SSD.

Micro fracture mechanisms that lead to SSD in brittle materials have been extensively investigated by Lawn. ${ }^{13}$ Median cracks commence and propagate with increase of indentation load. With indentation unloading, the median cracks close and lateral cracks grow towards the surface. These fracture mechanisms result in surface and subsurface defects.

Different models to predict SSD have been proposed using the maximum chip thickness and the material properties. $^{14}$ Other attempts to estimate the SSD have been proposed in order to correlate it with the abrasive grain size ${ }^{15}$ or the surface roughness. ${ }^{16}$ The importance of grinding machine performance ${ }^{17,18}$ has also been identified. Most recently, some work carried out on Zerodur ${ }^{\mathbb{B}}$ using a $25 \mu \mathrm{m}$ grit size grinding wheel introduced the separation of SSD into 'Process' related and 'Machine dynamics' related damage. ${ }^{19}$ 


\subsection{Subsurface damage evaluation techniques}

In order to measure the extent of subsurface cracks, different non-destructive and destructive measurement methods have been developed. Some non-destructive subsurface inspection techniques, ${ }^{20}$ such as ultrasonic Rayleigh wave measurement, have proved successful for information and qualification of significant and deep cracks.

Destructive methods have proved to be more successful for detecting micron and sub-micron scale fractures. Cross-sectional transmission electron microscope (TEM) analysis has shown good results for detection of submicron scale defects in glasses and crystals. ${ }^{21}$ This TEM process is however time consuming and less appropriate for large defects in multi-phase advanced ceramics. Repetitive polish, etch and optical microscopy have been widely employed to observe SSD in ground glasses. ${ }^{22} \mathrm{~A}$ variant of this repetitive polish and etch method $^{23}$ is a 'wedge' polishing approach which simplifies assessment of how defect density relates to depth beneath the ground surface. ${ }^{8}$

Two terms were employed to describe the subsurface damage level. The majority of subsurface cracks cluster together near the surface and terminate at a characteristic 'cluster depth'. A small minority of cracks propagate deeper beneath the surface. The 'single last fracture depth'15 is usually much deeper than the cluster.

\section{BOX GRINDING MACHINE}

The BoX ${ }^{\mathbb{B}}$ machine is a precision 3 axis grinding machine as shown in Figure 1.
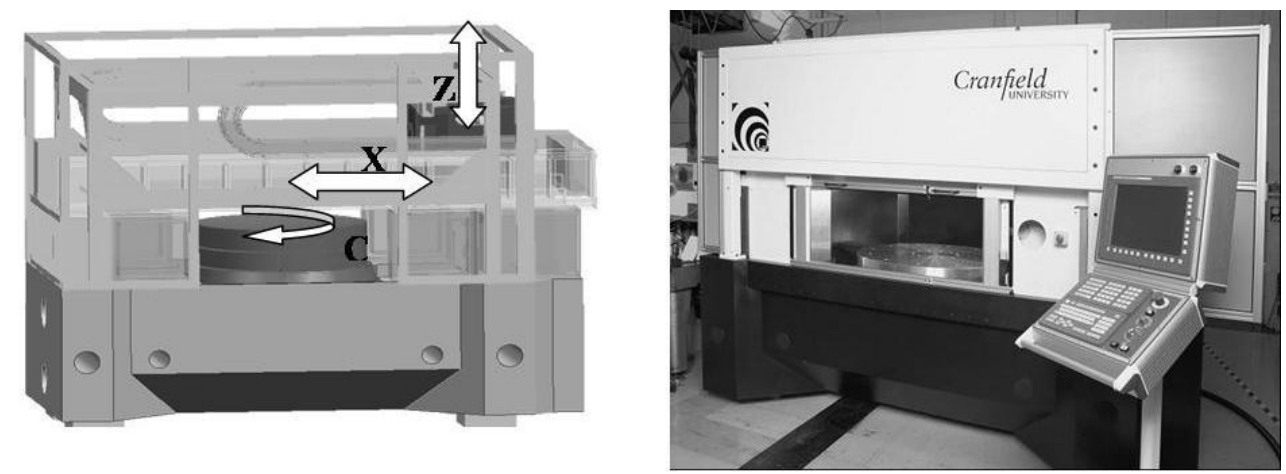

Figure 1. BoX ${ }^{\circledR}$ precision grinding machine

A vertically arranged $\mathrm{Z}$ linear axis sub-system carries a fixed inclination grinding spindle. The $\mathrm{Z}$ axis subsystem itself is mounted within a horizontal $\mathrm{X}$ linear axis carriage. A large rotary $\mathrm{C}$ axis table is employed to hold the workpiece. The grinding spindle is tilted at a fixed 20 degrees angle to enable machining of free-form optics $^{24}$ of slope up to 18 degrees. This maximum slope is considered suitable for the surfaces such as E-ELT segment and space telescope mirror geometries.

All bearings in the stressed loop of the BoX ${ }^{\circledR}$ machine are of a hydrostatic oil bearing type. The BoX ${ }^{(\mathbb{B})}$ has been designed to have high static $(>100 \mathrm{~N} / \mu \mathrm{m})$ and high dynamic loop stiffness (low moving mass $<750 \mathrm{~kg}$ with high 1 st resonant frequencies $>100 \mathrm{~Hz})$.

With these characteristics and an in situ measurement profilometer employing a 'non-stressed' metrology frame, a form accuracy of $1 \mu \mathrm{m}$ peak to valley is targeted with minimal levels of induced subsurface damage. In addition, the hydrostatic oil bearing grinding spindle has a $10 \mathrm{~kW}$ power capacity permitting a high material removal rate of $200 \mathrm{~mm}^{3} / \mathrm{s}$ to be achieved.

The machine is supported by temperature control systems with $+/-0.1^{\circ} \mathrm{C}$ control for the oil bearings, water cooling systems and grinding fluid. ${ }^{25}$ The grinding mode used does lead to a moving contact point that requires computation and compensation. This is achieved using an advanced control technique and system. ${ }^{26}$ 


\section{EXPERIMENTAL DETAILS}

\subsection{Materials}

Three materials have been studied in this project, Sintered Silicon Carbide (S/SiC), Zerodur ${ }^{\mathbb{B}}$ and ULE ${ }^{(\mathbb{B})}$. They were chosen due to their previously successful uses in the build of large optics. However, only two materials, $\mathrm{ULE}^{\mathrm{B}}$ and Zerodur ${ }^{\mathbb{B}}$, have been studied for SSD in this work. The SSD investigation of $(\mathrm{S} / \mathrm{SiC})$ requires additional development.

The material parameters important in the creation of subsurface damage are shown in Table 1.

\begin{tabular}{ccccc}
\hline Material & Elastic Modulus & Hardness & Fracture toughness & Brittleness \\
& $\mathrm{E}$ & $\mathrm{H}$ & $\mathrm{K}_{c}$ & $\mathrm{H} / \mathrm{K}_{c}$ \\
& $G P a$ & $G P a$ & Mpa.m $^{1 / 2}$ & $m^{1 / 2}$ \\
\hline ULE $^{(\mathbb{B}}$ & 70 & 4.6 & 1.8 & 2560 \\
Zerodur $^{(\mathbb{1}}$ & 91 & 6.2 & 0.9 & 6890 \\
\hline
\end{tabular}

Table 1. Zerodur ${ }^{\circledR}$ and $\mathrm{ULE}^{\circledR}$ parameters

Both ULE ${ }^{\mathbb{B}}$ and Zerodur ${ }^{\mathbb{B}}$ have low thermal expansion coefficients. The difference of fracture toughness and hardness between those two materials means that Zerodur ${ }^{\mathbb{B}}$ has a brittleness three times higher than ULE ${ }^{\mathbb{B}}$. $\mathrm{ULE}^{\mathbb{B}}$ (Ultra Low Expansion) is a glass material produced by Corning. Zerodur ${ }^{\circledR}$ is a glass ceramic material made by Schott.

\subsection{Specimens' size}

The specimens' size was $100 \mathrm{~mm}$ x $100 \mathrm{~mm}$ and $20 \mathrm{~mm}$ thick. The specimens were ground flat. The size was chosen to be small enough for SSD evaluation. The subsequent process validation was made on a $400 \mathrm{~mm} x$ $400 \mathrm{~mm}$ x $25 \mathrm{~mm}$ thick $\mathrm{ULE}^{\mathbb{B}}{ }^{\mathbb{B}}$ plate and on a $1 \mathrm{~m}$ across corners hexagonal Zerodur ${ }^{\circledR}$ part. Both specimens were ground spherical to a $3 \mathrm{~m}$ radius of curvature. This particular shape was chosen based on the available metrology.

\subsection{Grinding wheels}

Three 'toric' shaped resin bonded diamond cup grinding wheels have been evaluated. Each grinding wheel has a $325 \mathrm{~mm}$ outer diameter with an abrasive layer width of $60 \mathrm{~mm}$. Three grit sizes were chosen for this grinding process, $76 \mu \mathrm{m}, 46 \mu \mathrm{m}$ and $25 \mu \mathrm{m}$.

The grinding wheels' cross sectional form was trued and shaped to a $300 \mathrm{~mm}$ radius using a nickel electroplated diamond roller. The grinding wheels were balanced in-situ with a Schenck dynamic balancing system. They were dressed using a green carborundum stick. A slot type coolant nozzle ${ }^{27}$ was used. This provided consistent coolant laminar flow across the whole contact region between the specimen and the grinding wheel. The coolant used was Chemsearch Dowel diluted at $2 \%$ in water.

\subsection{Grinding parameters}

The grinding parameters controlled are the depth of cut $\left(a_{e}\right)$, the feed per revolution $\left(f_{r}\right)$, the surface speed $\left(v_{w}\right)$ and the cutting speed $\left(v_{c}\right)$. The material removal rate $\left(Q_{w}\right)$ was also calculated.

The grinding parameters employed for the tests carried out are shown in Table 2.

\begin{tabular}{|c|c|c|c|c|c|c|}
\hline $\begin{array}{l}\text { Grinding } \\
\text { Conditions }\end{array}$ & Grit size & $\begin{array}{c}\text { Depth of cut } \\
\qquad a_{e} \\
\mu m\end{array}$ & $\begin{array}{l}\text { Feedrate } \\
\qquad f_{r} \\
\mathrm{~mm} / \mathrm{rev}\end{array}$ & $\begin{array}{c}\text { Work speed } \\
v_{w} \\
m m / s\end{array}$ & $\begin{array}{c}\text { Cutting speed } \\
v_{c} \\
\mathrm{~m} / \mathrm{s}\end{array}$ & $\begin{array}{c}\text { MRR } \\
Q_{w} \\
\mathrm{~mm}^{3} / \mathrm{s}\end{array}$ \\
\hline Rough cut & 76 & 500 & 15 & 25 & 30 & 187.5 \\
\hline Semi Finish cut & 46 & 200 & 10 & 20 & 30 & 40 \\
\hline Finish cut & 25 & 50 & 1.5 & 25 & 30 & 1.87 \\
\hline
\end{tabular}


The rough cut removes the bulk material. A semi finish cut eliminates the amount of damage induced by the rough grinding. The first finish cut takes out the previous grinding damage. Finally, the second finish cut creates the final form accuracy, surface roughness and level of subsurface damage.

\subsection{Grinding mode}

The normal BoX ${ }^{\mathbb{B}}$ grinding mode generates a spiral curve. This type of grinding mode has previously been described in the use of the Large Optical Generator ${ }^{24}$ as well as the grinding of aspherical optical components. ${ }^{28}$ To simplify the roughness measurement along the grinding direction, the samples were set on the rotary table at a radius of $450 \mathrm{~mm}$.

This particular grinding mode is illustrated in Figure 2.

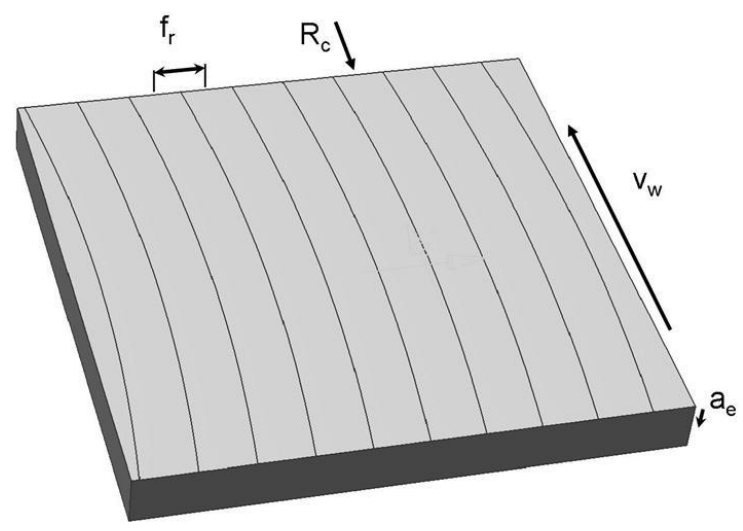

Figure 2. Semi finish grinding mode example

The fixture used was designed to be stiff and elevated the samples within reach of the $\mathrm{Z}$ axis stroke. This was necessary due to the samples' thickness compared to the large blanks typically used in BoX ${ }^{\mathbb{B}}$. The samples were held in position on a steel plate with 'wax'. This plate was bolted on a Kistler force dynamometer. For each experiment, the grinding forces were recorded in three orthogonal directions.

\section{EXPERIMENTS RESULTS}

\subsection{Grinding performance}

As previously mentioned, the finish cut creates the final form accuracy $\left(P_{t}\right)$, surface roughness $\left(R_{a}\right)$ and level of subsurface damage (SSD). Therefore, the three different grinding wheels were used to measure the output qualities for similar finish cuts.

The surface profile and surface roughness values obtained using the finish grinding condition, are shown in Figure 3 . 

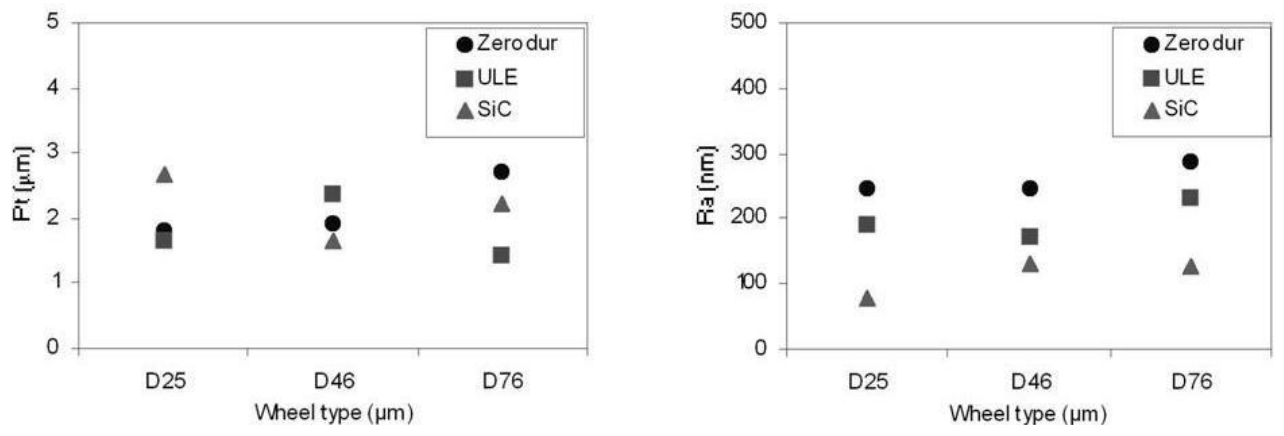

Figure 3. Surface profile $\left(P_{t}\right)$ and surface roughness $\left(R_{a}\right)$ results - Finish cut

For the surface profile, the Zerodur ${ }^{\circledR}$ tests show an increase when increasing the grinding wheel grit size. However, the rest of the tests do not show a specific trend across materials with different grinding wheels. The $P_{t}$ theoretical value can be calculated using the feed rate per revolution and the abrasive layer radius of curvature. Therefore, the machine dynamics as repositioning errors, are influencing more the surface profile results than the grit size.

The surface roughness along the grinding direction, $\left(R_{a}\right)$, changes with the grinding wheel grit size. Larger grit size results in an increase of the surface roughness for ULE ${ }^{\circledR}$ and S/SiC. Interestedly, for Zerodur ${ }^{\circledR}$, the D46 grinding wheel gives better results than the D25 grinding wheel.

\subsection{Process performance on large parts}

The results obtained on small test samples (Figure 3) demonstrate the grinding process output quality. The final accuracy achieved was $P_{t}<2 \mu \mathrm{m}$ and $R_{a}<250 \mathrm{~nm}$ for $\mathrm{ULE}^{\circledR}{ }^{\circledR}$ and Zerodur ${ }^{\circledR}$. Meanwhile, for $\mathrm{S} / \mathrm{SiC}$, the results are $P_{t}<3 \mu \mathrm{m}$ and $R_{a}<100 \mathrm{~nm}$.

This process was subsequently replicated on larger parts.

First, a $400 \mathrm{~mm} \times 400 \mathrm{~mm} \times 25 \mathrm{~mm}$ ULE ${ }^{\mathbb{B}}$ part was successfully machined from a flat to a $3 \mathrm{~m}$ radius of curvature sphere. Thereafter, a $3 \mathrm{~m}$ radius of curvature was ground into a 1 metre across corner hexagonal Zerodur ${ }^{\circledR}$ part. An intermediate rough grinding surface and the final ground surface are shown in Figure 4a and 4b respectively.

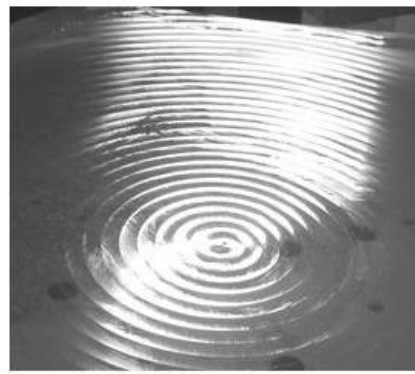

a) Rough grinding cut

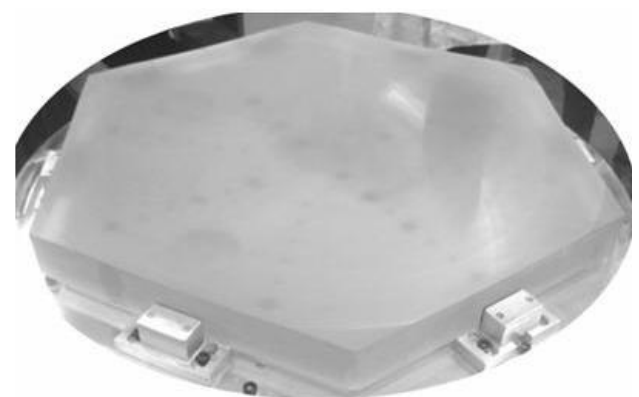

b) Finish grinding cut

Figure 4. 1 metre Zerodur ${ }^{(\mathbb{B}}$ part ground surfaces

The 1 metre Zerodur ${ }^{\circledR}$ part was ground from a flat to a $3 \mathrm{~m}$ radius of curvature sphere removing a $32 \mathrm{~mm}$ saggitta. The final ground surface was measured using a Leitz PMM-F co-ordinate measuring machine. This CMM is located in the Hexagon Loxham Precision Laboratory at Cranfield University.

The target form accuracy of $\pm 1 \mu \mathrm{m}$ was achieved.

An error compensation approach can be implemented to achieve a better final ground surface form accuracy. 
The final $0.5 \mathrm{~mm}$ was removed in less than 10 hours proving the efficiency of the grinding process developed. 'Flash' polishing using a Zeeko IRP1200 polishing machine was subsequently carried out to improve roughness thereby allowing an interferometer to be employed.

The interferogram obtained is shown in Figure 5.

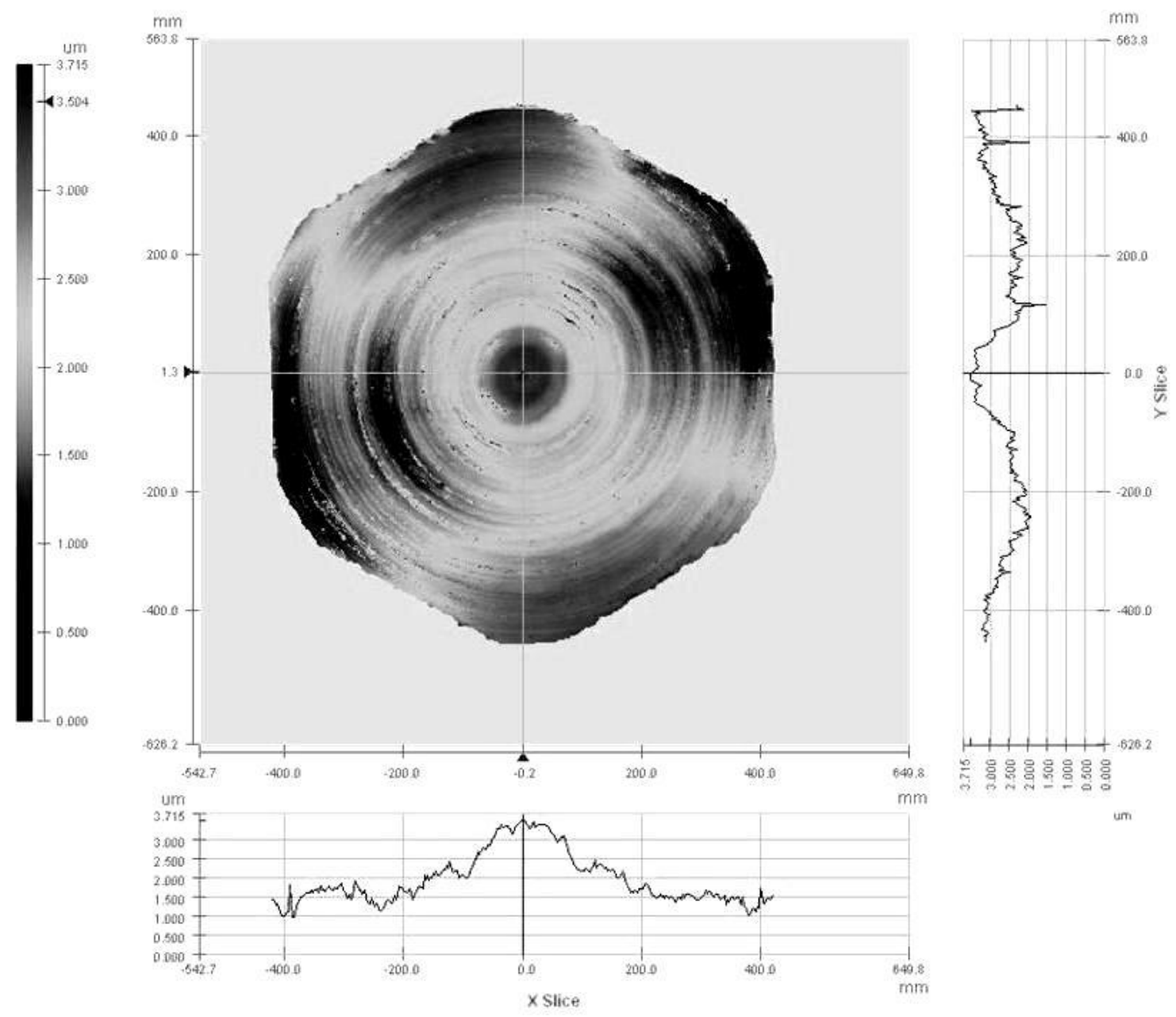

Figure 5. Ground part after interferogram 'Flash' polishing

The interferogram gives a form accuracy of $\mathrm{PV}=3.715 \mu \mathrm{m}\left(P V_{q(99 \%)}=2.62 \mu \mathrm{m}\right)$ and a surface roughness of $632 \mathrm{~nm}$ RMS.

\section{SUBSURFACE DAMAGE RESULTS}

\subsection{Subsurface evaluation technique}

The subsurface damage was observed using a polishing process. A tapered groove was made parallel to the grinding direction using a Zeeko IRP polishing machine. ${ }^{29}$

The evaluation technique is illustrated in Figure 6. 


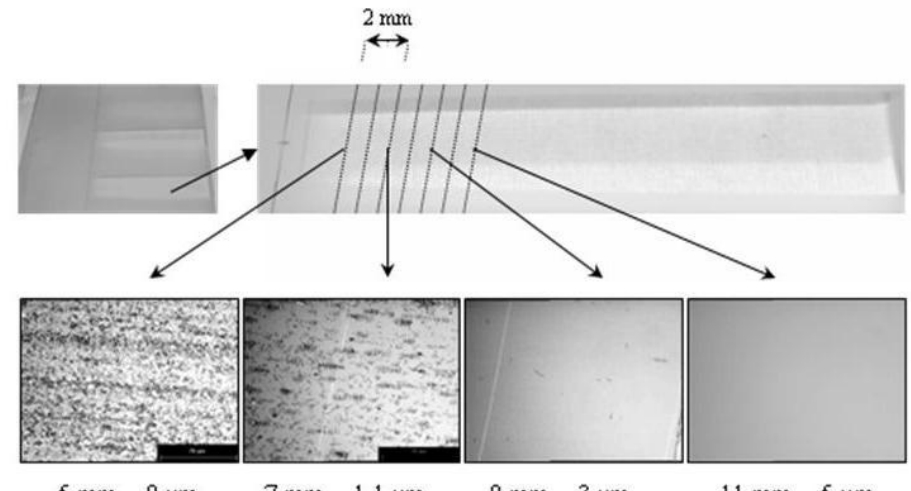

$5 \mathrm{~mm}-0 \mu \mathrm{m}$

$7 \mathrm{~mm}-1.1 \mu \mathrm{m}$

$9 \mathrm{~mm}-3 \mu \mathrm{m}$

$11 \mathrm{~mm}-5 \mu \mathrm{m}$

a) Sample 1 - groove 2 - D25 - ULE

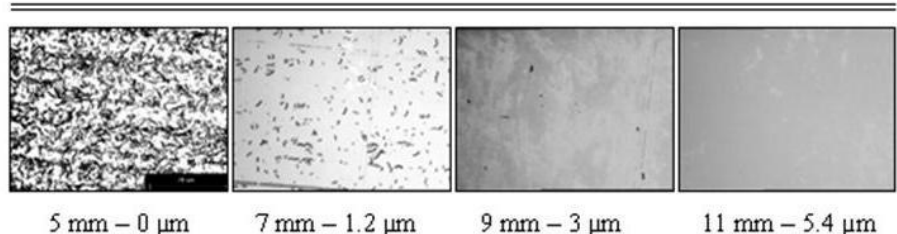

b) Sample 1 - groove 2 - D25 - Zerodur ${ }^{(2)}$

Figure 6. Subsurface damage evaluation technique

The grooves were polished along the grinding direction. Two grooves were made to average the subsurface damage values obtained. The polished tapered grooves were etched using $\mathrm{HF}$ and $\mathrm{HCl}$ acids for 10 seconds duration. The etching period was set to remove less than $1 \mu \mathrm{m}$ from the ground and polished surface. A Form Talysurf profilometer was used to measure the depth of the groove at each measurement position. The surfaces were observed and the number of cracks counted using an optical microscope. The number of cracks per mm ${ }^{2}$ against the depth under the ground surface were plotted. Those were used to investigate the possible separation of SSD into Process related and Machine dynamics related. ${ }^{19}$

\subsection{Subsurface damage measurements}

The subsurface damage cracks have different shapes and sizes in $\mathrm{ULE}^{\left({ }^{\circledR}\right.}$ and in Zerodur ${ }^{\circledR}$. An example of SSD cracks created with a D25 grinding wheel are shown in Figure 7.
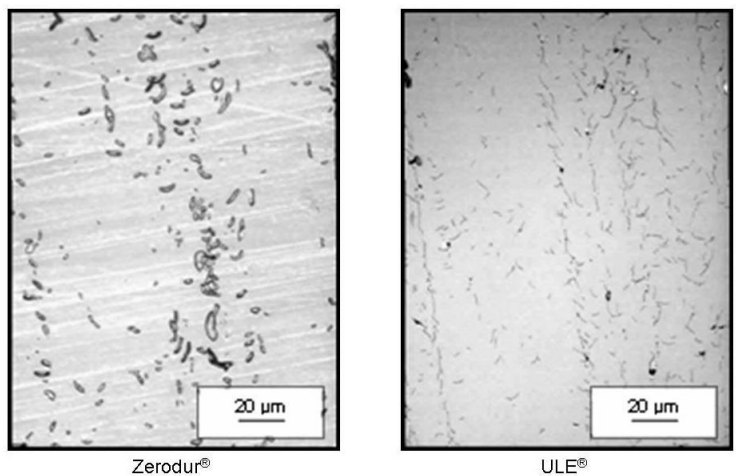

Figure 7. Subsurface damage cracks using a D25 grinding wheel 
The Zerodur ${ }^{\mathbb{B}}$ cracks are small and slightly curved. However, the ULE ${ }^{\mathbb{B}}$ cracks are much longer. They also overlap each other and have a more 'fork type' shape. The cracks length to thickness ratio is also larger for $\mathrm{ULE}^{\mathrm{B}}$ than Zerodur ${ }^{\mathbb{B}}$.

The 'cluster' and 'single last fracture' depths results are shown in Table 3.

\begin{tabular}{cccccc}
\hline & \multicolumn{2}{c}{ Cluster depth } & & \multicolumn{2}{c}{ Single last fracture depth } \\
\cline { 2 - 3 } \cline { 5 - 6 } Grinding & $\mathrm{ULE}^{\mathbb{B}}$ & Zerodur $^{\circledR}$ & & $\mathrm{ULE}^{\circledR}$ & $\begin{array}{c}\text { Zerodur } \\
\text { Conditions }\end{array}$ \\
& $\mu m$ & $\mu m$ & & $\mu m$ & $\mu m$ \\
\hline Rough cut (D76) & 8.5 & 5 & & 18.5 & 8 \\
Semi Finish cut (D76) & 6 & 5 & & 11 & 12 \\
Semi Finish cut (D46) & 4.5 & 4 & & 9 & 7.5 \\
Semi Finish cut (D25) & 5 & 7 & & 11.5 & 10 \\
Finish cut (D76) & 7 & 6.5 & & 14 & 13.5 \\
Finish cut (D46) & 6 & 4 & & 10 & 11 \\
Finish cut (D25) & 4 & 3 & & 8 & 4 \\
\hline
\end{tabular}

Table 3. Grinding parameters

Importantly, the finish cut using a D25 grinding wheel leaves $8 \mu \mathrm{m}$ in ULE $^{(\mathbb{B}}$ and $4 \mu \mathrm{m}$ in Zerodur ${ }^{\mathbb{B}}$. During the rough cut (D76), the single last fracture depth is more than twice the depth in ULE ${ }^{\left({ }^{B}\right.}$ than Zerodur ${ }^{\mathbb{B}}$. However, the finish cut (D46) and semi finish cut (D76) give more damage in Zerodur ${ }^{\circledR}$. Overall, subsurface damage depths in $\mathrm{ULE}^{\circledR}$ are larger than in Zerodur ${ }^{\circledR}$.

The cluster depth results show the same trend between both materials as for the single last fracture depth. This depth difference is typically within 1-2 $\mu \mathrm{m}$. Those results are in accordance with the consideration that the single last fracture depth is machine dynamics related while the cluster depth is process related.

The important subsurface damage values are those created during the finish cuts. Results highlight that reducing the grinding wheel grit size reduces the subsurface damage level. The finish cuts using $25 \mu \mathrm{m}$ grit size reach the target value for Zerodur ${ }^{\circledR}(<5 \mu \mathrm{m})$ but not for $\mathrm{ULE}^{\circledR}$.

\section{CONCLUSIONS}

This paper shows the results obtained on optical materials using the BoX ${ }^{\mathbb{B}}$ grinding mode. An efficient grinding process has been developed for precision grinding of large optics.

On Zerodur ${ }^{\circledR}$, the final profile accuracy $\left(P_{t}\right)$ obtained is $\pm 1 \mu \mathrm{m}$ over a metre. The surface roughness $\left(R_{a}\right)$ and subsurface damage level obtained are $247 \mathrm{~nm}$ and $4 \mu \mathrm{m}$ respectively. On ULE ${ }^{\mathbb{B}}, R_{a}$ and SSD level obtained are $191 \mathrm{~nm}$ and $8 \mu \mathrm{m}$ respectively.

The total grinding process time achievable to remove $0.5 \mathrm{~mm}$ from a pre-shaped optical blank is 10 hours. Further work will be carried out on the influence of grinding machines dynamics on induced subsurface damage levels in optical surfaces.

\section{ACKNOWLEDGMENTS}

The authors would like gratefully to acknowledge both funding support from the McKeown Precision Engineering and Nanotechnology Foundation at Cranfield and project funding through the UK's Joint Research Councils' Basic Technologies programme and EPSRC funded Integrated Knowledge Centre for UPS ${ }^{2}$.

\section{REFERENCES}

[1] Dierickx, P., Brunetto, E. T., Comeron, F., Gilmozzi, R., Gonté, F. Y. J., Koch, F., le Louarn, M., Monnet, G. J., Spyromilio, J., Surdej, I., Verinaud, C., and Yaitskova, N., "OWL phase - A status report," in [Proceedings of the SPIE], 5489, 391-406 (2004).

[2] Gilmozzi, R. and Spyromilio, J., "The European Extremely Large Telescope (E-ELT)," ESO Messenger 127, 11-19 (2007). 
[3] Gilmozzi, R., "Science and technology drivers for future giant telescopes," in [Proceedings of the SPIE], 5489, 1-10 (2004).

[4] Shore, P. and May-Miller, R., "Production Challenge of the Optical Segments for Extra Large Telescopes," in [Proceedings Of The International Workshop On Extreme Optics And Sensors], (40), 25 (2003).

[5] Shore, P., Morantz, P., Luo, X., Tonnellier, X.and Read, R., and May-Miller, R., "Design philosophy of the ultra precision big optix "BoX" machine," in [Proceedings of Landamap Conference], 200-209 (2005).

[6] Tonnellier, X., Shore, P., Luo, X., Morantz, P., and Baldwin, A., "High performance grinding studies on optical materials suitable for large optics," in [Proceedings of 2nd CIRP conference on HPC], (2006).

[7] Tonnellier, X., Shore, P., Luo, X., Morantz, P., Baldwin, A., Jin, T., and Stephenson, D., "Wheel wear investigations when precision grinding of optical materials using the BoX grinding mode," in [Proceedings of 5th International Conf. on HSM], 177-187 (2006).

[8] Tonnellier, X., Shore, P., Luo, X., Morantz, P., Baldwin, A., Evans, R., and Walker, D., "Wheel wear and surface/subsurface qualities when precision grinding optical materials," in [Proceedings of the SPIE], 6273, 627308 (2006).

[9] IKC, "http://www.ups2.co.uk - accessed 05/08," (2008).

[10] Inasaki, I., "Grinding of hard and brittle materials," CIRP annals 36(2), 463-471 (1987).

[11] Bifano, T. G., Dow, T. A., and Scattergood, R. O., "Ductile-regime grinding : a new technology for machining brittle materials," Journal of Engineering for Industry 113(2), 184-189 (1991).

[12] Shore, P., McKeown, P., Impey, S., and Stephenson, D., "Surface and near surface conditions of "ductile" mode ground Zerodur," in [Proceedings of 8th International Precision Engineering Seminar], 365-368 (1995).

[13] Lawn, B. R. and Wilshaw, T. R., [Fracture of brittle solids], Cambridge university press (1975).

[14] Maksoud, T. M. A., Mokbel, A. A., and Morgan, J. E., "Evaluation of surface and sub-surface cracks of ground ceramic," Journal of Materials Processing Technology 88, 222-243 (1999).

[15] Lambropoulos, J. C., "From abrasive size to subsurface damage in grinding," OSA Technical Digest 8, 17-18 (2000).

[16] Hed, P. P. and Edwards, D. F., "Optical glass fabrication technology 2: Relationship between surface roughness and subsurface damage," Appl. Opt. 26/21, 4677-4680 (1987).

[17] Franse, J., Aspects of Precision Grinding, PhD thesis, Technische Universiteit Eindhoven (1991).

[18] Shore, P., Machining of optical surfaces in brittle materials using an ultra-precision machine tool, $\mathrm{PhD}$ thesis, Cranfield University (1995).

[19] Tonnellier, X., Morantz, P., Shore, P., Baldwin, A., Evans, R., and Walker, D., "Subsurface damage caused during rapid grinding of Zerodur," Advances in Abrasive Technology 10, $\mathrm{xx}-\mathrm{xx}(2007)$.

[20] Tonshoff, H. K., Brinksmeier, E., and Hetz, F., "Detection of microcracks," CIRP annals 36(2), 545-552 (1987).

[21] Puttick, K. E., Jeynes, C., Whitmore, L., Rudman, M. R., Yamasaka, M., Shore, P., and Gee, A. E., "Surface damage in nanoground silicon," in [Proceeding of IMECH], 49-51 (1992).

[22] Ball, M. J., Murphy, N. A., and Shore, P., "Electrolytically assisted "ductile" mode diamond grinding of BK7 and SF10 optical glasses," in [Proceedings of the SPIE], 1573, 30-38 (1991).

[23] Sun, X., Stephenson, D. J., Ohnishi, O., and Baldwin, A., "An investigation into parallel and cross grinding of BK7 glass," Journal of Precision Engineering 30, 145-153 (2006).

[24] Parks, R. E., "Two approaches to generating Free-Form optics," in [Proceedings of ASPE], 88-93 (2004).

[25] Carlisle, K. and Shore, P., "Review of the ultra precision machining research facility the nion machine," in [Proceedings of UME3], 89-93 (1994).

[26] Shore, P., Luo, X., Jin, T., Tonnellier, X., Morantz, P., Stephenson, D., Collins, R., Roberts, A., May-Miller, R., and Read, R., "Grinding mode of the BOX ultra precision free-form grinder," in [Proceedings of ASPE], (2005).

[27] Webster, J. A., Cui, C., and Mindek Jr, R. B., "Grinding Fluid Application System Design," CIRP annals 44(1), 333-338 (1995).

[28] Kuriyagawa, T., Zahmaty, M. S. S., and Syoji, K., "A new grinding method for aspheric ceramic mirrors," Journal of Materials Processing Technology 62(4), 387-392 (1996).

[29] Walker, D., Beaucamp, A. T., Brooks, D., King, A., Morton, R., and McCavana, G., "New polishing technology for large mirrors and lenses," in [Proceedings of the SPIE], TD02, 31-35 (2003). 